\title{
A SISTEMÁTICA DOS EFEITOS DA SUPLEMENTAÇÃO DE GLUTAMINA NA SÍNDROME DO INTESTINO CURTO COMO ELEMENTO DE GESTÃO NA ÁREA DE NUTRIÇÃO CLÍNICA: SÍNTESE DE EVIDÊNCIAS
}

The systematics of glutamine supplementation effects in short-intestine syndrome as a management element in the clinical nutrition area: summary of evidence

Luciana Pereira Rocha da Silva ${ }^{1}$, Vanessa Fernandes Coutinho ${ }^{2}$, William Malagutti ${ }^{3}$, Francisco Sandro Menezes Rodrigues ${ }^{4}$, Renato Ribeiro Nogueira Ferraz ${ }^{5}$

${ }^{1-3}$ Universidade Estácio de Sá - São Paulo - SP. ${ }^{4}$ Universidade Federal de São Paulo São Paulo - SP. ${ }^{5}$ Universidade Nove de Julho - SP.

\section{RESUMO}

Introdução: As situações metabólicas que cursam com distúrbios nos processos de digestão e absorção, acarretam vários prejuízos ao equilíbrio do organismo A retirada de 70 a $75 \%$ nos segmentos do intestino poderá resultar em doenças que acarretam diversas carências. Quando a ressecção é no colón, aumenta a gravidade do quadro, sendo caracterizada como síndrome do intestino curto (DE OLIVEIRA COSTA et al., 2015). Objetivo: Avaliar a utilização da suplementação de glutamina na síndrome do intestino curto associada à desnutrição. Método: Utilizando o Publish or Perish para pesquisa de trabalhos com maior relevância no meio acadêmico, foi realizada a leitura e compreensão desses artigos para um melhor entendimento sobre o assunto em questão. Conclusão: O uso de glutamina melhora o papel protetor da barreira intestinal, além de aumentar a vida dos tecidos da musculatura intestinal.

Palavras-chave: Gestão em Saúde, Intestino Curto, Desnutrição, Suplementação, Glutamina.

\begin{abstract}
Introduction: Metabolic situations that occur with digestion disorders and absorption processes, cause several damages to the balance of organism. The withdrawal of 70 to $75 \%$ in the intestine segments can result in diseases that lead to several deficiencies. When the resection is in the colon, it increases the severity of condition, being characterized as short bowel syndrome. Objective: To evaluate the use of glutamine supplementation in short bowel syndrome associated with malnutrition. Method: Using Publish or Perish to search for articles with greater relevance in the academic environment, that were for a better subject understanding. Conclusion: The use of glutamine improves the protective role of intestinal barrier, in addition to increasing the life of intestinal musculature tissues. Keywords: Short Intestine, Malnutrition, Supplementation, Glutamine.
\end{abstract}

\section{INTRODUÇÃO}

As situações metabólicas que cursam com distúrbios nos processos de digestão e absorção, acarretam vários prejuízos ao equilíbrio no organismo. A retirada de 70 a $75 \%$ dos segmentos do intestino poderá resultar em processos de carência alimentar. Quando a ressecção é no colón, aumenta a gravidade do quadro, sendo esta denominada síndrome do intestino curto (DE OLIVEIRA COSTA et al., 2015).

A síndrome do intestino encurtado, ou síndrome do intestino curto (SIC), decorre da ressecção de extensos segmentos intestinais, sendo caracterizada pela deficiência absorção intestinal de vários nutrientes (TANNURI, 2004).

Existe maior incidência da SIC em países desenvolvidos. Na Europa e nos EUA, a doença está vigente em cerca de 12,7 e 120 indivíduos por um milhão de habitantes ao ano, respectivamente. No Canadá, há cerca de quatro crianças com essa afecção por um 
milhão de habitantes ao ano. O Brasil ainda não dispõe ainda de dados estatísticos que possam demonstrar a real incidência da SIC (DE OLIVEIRA COSTA et al., 2015).

O intestino delgado é o principal sítio de metabolização da glutamina. Nele ocorre a regularização do balanço nitrogenado. A glutamina é um aminoácido essencial no processo de estresse do organismo (XAVIER et al., 2012), e uma revisão sobre os seus efeitos na SIC pode contribuir para um melhor entendimento da carência nutricional comum a seus portadores.

\section{OBJETIVO}

Realizar uma revisão da literatura sobre a utilização da suplementação de glutamina na desnutrição observada na SIC.

\section{MÉTODO}

Trata-se de uma revisão da literatura com síntese em evidências, realizada com o auxílio da ferramenta computacional Publish or Perish, no mês de agosto de 2017, utilizando os seguintes descritores: "Glutamina AND Síndrome do Intestino Curto AND desnutrição AND suplementação".

\section{RESULTADOS}

A revisão literária foi concluída no mês agosto de 2017. Um total de 25 artigos foram encontrados e, após a leitura cuidadosa dos resumos, apenas 16 artigos foram selecionados. As obras excluídas não atendiam adequadamente a temática deste assunto.

\section{REVISÃO DE LITERATURA}

As ressecções proximais são capazes de provocar déficits na síntese dos hormônios, gastrina, colecistoquinina e secretina, e também déficits na absorção de lipídios e vitaminas lipossolúveis, particularmente a vitamina $\mathrm{D}$, contribuindo assim para deficiência de cálcio. $O$ intestino delgado é um órgão revestido pela camada de epitélio prismático simples, aderido à lamina própria do tecido conjuntivo frouxo (WAITZBERG, 2006). Com a ressecção inteiriça do intestino delgado, a parte conservada sofre, com o tempo, várias adaptações como o espessamento da parede, dilatação e redução da motilidade (PECK et al., 2012).

É fato que com o aumento da ingestão oral de nutrientes, se torna mais fácil suprir suas necessidades de eletrólitos e íons bivalentes. Por isso, a absorção de energia se converte em um fator limitante quando intestino é muito curto, ou seja, quando o jejuno é menor que $70 \mathrm{~cm}$, gerando desnutrição, fator determinante para o aumento da mortalidade e morbidade (NONINO et al., 2001). Refeições fracionadas em pequenos volumes são úteis na readaptação intestinal do paciente portador de SIC (NONINO et al., 2001).

A glutamina é um aminoácido neutro, também conhecido como ácido 2aminoglutarâmico. Possui cinco átomos de carbono e dois de nitrogênio, constituindo de 30 a 35\% dos aminoácidos do sistema circulatório, com papel fundamental no transporte de nitrogênio entre os órgãos. Apesar de existirem grandes depósitos de glutamina nos músculos, as reservas endógenas podem diminuir em adultos e crianças durante aumentos catabólicos, como septicemia, queimaduras extensas e grandes cirurgias. $\mathrm{O}$ crescimento metabólico aumenta sua capacidade de síntese, sendo necessária a suplementação da dieta e, com isso, a glutamina é sendo classificada com um aminoácido essencial (PACÍFICO; LEITE; CARVALHO, 2005). A glutamina está sendo usada para aumentar a resposta imunológica (ALBERTINI; RUIZ, 2001). O trato gastro intestinal é o principal órgão de utilização da glutamina, essencialmente nas células epiteliais dos vilos do intestino delgado (CRUZAT et al., 2009). O agrupamento de glutamina no sangue se reduz consideravelmente em doenças graves, levando a um estado de diminuição em até $75 \%$ 
desse aminoácido na concentração intracelular do músculo estriado, estando este fato relacionado ao aumento da mortalidade. São controversas as informações sobre a melhor apresentação de glutamina a ser oferecida, nem sobre e qual seria a melhor dosagem a ser utilizada. O organismo sadio utiliza diariamente cerca de 19 a 23 g de glutamina (WILMORE, 2001). Sabe-se que $20 \mathrm{~g} /$ dia ou $0,5 \mathrm{~g} /$ peso são necessários para normalizar sua concentração. Em via enteral, a glutamina poderá ser utilizada como substrato energético nas células e na mucosa intestinal. No ano de 2000 , verificou-se que a glutamina apresentava um efeito bloqueador da barreira intestinal, em um período prévio a lesão, indicando que este aminoácido pode exercer papel protetor, aparentemente profilático, sobre a barreira intestinal (SALVALAGGIO, 2000).

\section{SÍNTESE DE EVIDÊNCIAS}

O uso da glutamina em pacientes com Síndrome do Intestino Curto parece induzir melhora no papel protetor da barreira intestinal. Com o estresse do organismo, ocorre a diminuição no processamento da glutamina, e com essa diminuição, poderá haver perda de massa muscular. Os estudos avaliados divergem em relação à dosagem ideal de suplementação, sendo $0.5 \mathrm{~g} / \mathrm{kg}$ ao dia a mais citada, embora não se tenha chegado a uma quantidade ideal a ser suplementada ao paciente para a normalização do processo oxidativo.

\section{REFERÊNCIAS}

ALBERTINI, S. M.; RUIZ, M. A. O papel da glutamina na terapia nutricional do transplante de medula óssea. Rev. bras. hematol. hemoter, v. 23, n. 1, p. 41-7, 2001.

CRUZAT, V. F. et al. Glutamina: aspectos bioquímicos, metabólicos, moleculares e suplementação. Revista Brasileira de medicina do Esporte, v. 15, n. 5, p. 392-397, 2009.

DE OLIVEIRA COSTA, I. F. et al. Terapia Nutricional e Uso de Glutamina, Citrulina, Arginina e Probióticos na Síndrome do Intestino Curto. Journal of Health Sciences, v. 14, n. 1, 2015.

NONINO, C. B. et al. Terapia nutricional oral em pacientes com Síndrome do Intestino Curto. Revista de Nutrição, v. 14, n. 3, p. 201-205, 2001.

PACÍFICO, S. L.; LEITE, H. P.; CARVALHO, W. B. DE. A suplementação de glutamina é benéfica em crianças com doenças graves? Revista de Nutrição, 2005. Disponível em: $<$ http://www.repositorio.unifesp.br/handle/11600/2414>. Acesso em: 3 set. 2017.

PECK, J. et al. Short bowel syndrome: the pathophysiology and treatment. Gastrointestinal Nursing, v. 10, n. 2, p. 32-38, 1 mar. 2012.

SALVALAGGIO, P. R. DE O. Efeito da glutamina sobre a translocação bacteriana em ratos com oclusão intestinal. 2000. Disponível em: $<$ http://www.acervodigital.ufpr.br/bitstream/handle/1884/8499/PAOLO\%20ROGERIO $\% 20 \mathrm{DE} \% 20 \mathrm{OLIVEIRA} \% 20$ SALVALAGGIO_2000.pdf?sequence=1>. Acesso em: 3 set. 2017.

TANNURI, U. Short bowel syndrome in children: Treatment with home parenteral nutrition. Revista da Associação Médica Brasileira, v. 50, n. 3, p. 330-337, 2004.

WAITZBERG, D. L. Nutrição oral, enteral e parenteral na prática clínica. Atheneu, 2006. 
WILMORE, D. W. The effect of glutamine supplementation in patients following elective surgery and accidental injury. The Journal of nutrition, v. 131, n. 9, p. 2543S-2549S, 2001.

XAVIER, H. et al. Relação do consumo de glutamina na melhora do trato gastrointestinal-revisão sistemática. O papel da glutamina no trato gastrointestinal. RBONE-Revista Brasileira de Obesidade, Nutrição e Emagrecimento, v. 3, n. 18, 2012. 